BOOK REVIEW

\section{Intimate Wars. The Life and Times of the Woman Who Brought Abortion From the Back Alley to the Boardroom}

Merle Hoffman.New York, NY, USA:The Feminist Press at the City University of New York,2012. ISBN-13: 978-1-55861-751-3. Price: f13.99. Pages: 336 (paperback)

Merle Hoffman is a woman who is not afraid of controversy or criticism. She is bold, courageous, principled and outspoken and has unwavering commitment in support of women's rights and especially abortion as a positive reproductive health choice. This has been her life's work and there is much to admire. I first heard her on Woman's Hour in March 2012 - she made me sit up and listen. Her book, a memoir, is the story of what she describes as a mixed life - as an activist, a philosopher and a transgressor of boundaries enriched with allies, friends, lovers and family.

Born in the USA in 1946, Meryl (later changed to the "more powerfully androgynous Merle") Holly Hoffman was born to an autocratic mother and a gentle father. Her mother's frustrated ambitions to compete, excel and perform in dance were transferred to her daughter to be the performer she never was. As an only child Merle created her own internal world, escaping her mother's desires though fantasy and by identifying with strong historical characters. Gifted with a musical talent and trained from an early age to be a concert pianist, it was at this time she learned to value criticism and discipline. However, music was not to be her life and later when she noticed that "parallel to the life I was living, another world was coming into being: the women's liberation movement was gathering storm". She felt isolated and groundless and did not identify herself with the "band of angry young women who were calling themselves feminists". Abortion in the 1960 s was illegal in the USA but the battle for abortion rights sparked something in Merle; she saw something in these women who exhibited the qualities of courage, creativity and integrity of purpose that she herself yearned to find and express.

A part-time position as a medical assistant in a small medical office in Queens, New York was the first step in Merle taking up the baton for women's rights. While working she studied psychology and during this time she experienced political and feminist activism, listening to women such as Anais Nin and Florynce Kennedy. It was Florynce who spoke the famous line: "If men could get pregnant, abortion would be a sacrament". In February 1971, the American Bar Association officially supported a woman's right to choose abortion up to the twentieth week of pregnancy. The Supreme Court's Roe v Wade decision in 1973 legalised the procedure in the USA. This brought women out of "blood stained alleys ... it thrust abortion into the traditional American medical system of health care". Importantly, it initiated the Women's Health movement as a defined phenomenon because it created a visible, observable, demanding reality about the need for gynaecological and abortion services. As a result, Flushing Women's Medical Center was opened and became one of the first abortion clinics in New York run by Dr Gold (later Merle's husband) and Merle. Having graduated in psychology and completed a postgraduate programme in social psychology and now skilled in business, management and finance, Merle became executive director of the clinic.

Providing abortion was new to Merle, in fact to most medical practitioners, and she embraced the challenge and every day talked, helped, counselled and supported fearful and vulnerable women. This was at a time when the general ignorance regarding women's bodies, health and sexuality was enormous; the Boston Women's Health Book Collective influential women's health book Our Bodies Ourselves was not yet published. Merle was also to encounter medical politics where abortion was "shoved to the lowest rung of the ladder". Working with so many women she saw "the trail of pregnancies caused by doctors' misinformation, ignorance or carelessness"; she could also see how being a woman meant you were immediately pathologised. Menstruation, sex, pregnancy, abortion, what method of contraception you had, whether or when to have children, how to raise and feed them all relied on a doctor's knowledge. As such, women were powerless having things "done to them rather than with them". She realised that women needed a stronger voice - they needed patient power and the ability to have their say in medical decisions and reproductive health.

Merle became more active in the women's movement, becoming President of the National Association of Abortion Facilities; this later joined with the National Abortion Council to become the National Abortion Federation where she was first secretary. As Merle became more involved in feminism and the pro-choice movement she witnessed the two sides of abortion emerge and collide: "the right to life", where the fetus comes first, or the "right to choose", where the fetus comes second. These are not mutually exclusive and Merle argues that the political debate has to find a way to navigate these narratives when in reality choice is "sometimes not a choice at all. It is an outcome determined by the economic, physical, sociological and political factors that surround women and move them towards the only action that allows them to survive at that point in their lives".

Recognising that abortion is one part of a woman's life she founded 'Choices' (Creative Health Organization for Information Counseling and Educational Services) Women's Medical Center in 1971. From the late 1970s, the USA experienced a huge backlash against abortion, daily picketing of abortion clinics, attacks on abortion clinics and in 1993 the first of a sequence of murders of abortion providers. Increasing presidential and political intervention, the release of Bernard Nathanson's film Silent Scream, the founding of Operation Rescue and other anti-choice organisations all added to constant harassment and this had a huge effect on reducing the number of physicians wanting to work in abortion. Many of the early physicians, whose commitment was formed by the experience of illegal abortion, were retiring or dead. During all this Merle continued to campaign, provide critical comment and speak out on abortion and reproductive rights. She launched On the Issues magazine in 1983 addressing pro-choice issues, and in 1985 she founded the New York ProChoice Coalition, the first umbrella organisation of pro-choice individuals, politicians, activists, providers and organisations committed to ensuring legal, safe abortion in New York. The imagery of the coat hanger (representative of all the awful home use remedies for abortion) was used by Merle in her work and this became a ubiquitous symbol of reproductive rights and remains a powerful visual cue.

This short review cannot do justice to the work and life of Merle Hoffman, her work, influence, commitment and unfailing courage in supporting women and reproductive health choices. All who work in reproductive health should read this passionate and powerful book. As Merle says: "Abortion cannot be simplified, refusing to look the consequences or true nature of abortion reduces our capacity to register the depth of this issue and disrespects the profound political and social struggle women's choices engender in our society".

Reviewed by Toni Belfield

Specialist in Sexual Health Information, Brook, UK; toni-b@tiscali.co.uk

J Fam Plan Reprod Health Care 2013;39:54. doi:10.1136/ffprhc-2012-100529 